\title{
Intrapartum hypoxia: the association between neurological assessment of damage and abnormal excretion of ATP metabolites
}

\author{
RA HARKNESS, AGL WHITELAW, ${ }^{*}$ RJ SIMMONDS \\ From the Division of Perinatal Medicine, Medical Research Council Clinical Research Centre, Watford Road, \\ Harrow HA1 3UJ, Middlesex
}

SUMMARY A series of 29 newborn infants had been studied after intrapartum hypoxia defined as meconium aspiration, an Apgar score of $\leqslant 6$ at $5 \mathrm{~min}$ or a peripheral blood pH of $7 \cdot 2$ or less after resuscitation. Two independent sets of techniques were used; one concerned with the critical system in hypoxic damage, the central nervous system, the other assessing the central biochemical events in hypoxia. Both sets of data were assembled, then graded separately and only then combined. In this way detailed neurological assessment has been combined with measurement of urinary excretion of the ATP metabolites, hypoxanthine and xanthine. The essential metabolic consequence of hypoxia is a reduction in the synthesis of the energy currency of cells, ATP. This is associated with an outflow of ATP metabolites from cells.

The extent of neurological damage was related to the magnitude of the hypoxanthine and xanthine excretion; neither were closely related to the initial blood $\mathrm{pH}$. Infants who were normal neurologically had normal oxypurine excretion. Infants wth neurological abnormalities for less than $48 \mathrm{~h}$ had lower excretion than those who were abnormal for more than $48 \mathrm{~h}$.

The duration of abnormal oxypurine excretion after an acute episode of hypoxia was studied in two infants with respiratory distress and in two other infants with apnoeic attacks. Severe hypoxia was followed by abnormal oxypurine excretion for at least $40 \mathrm{~h}$ after an acute episode. It is justifiable to suggest that abnormalities of oxypurine excretion should indicate intrapartum hypoxia in newborn infants. This excretion should also quantify the metabolic damage.

Intrauterine hypoxia is one of the main contributors to perinatal morbidity and mortality and to persistent neurological impairment.' There is also evidence of its possible importance to the pathogenesis of speech and language ${ }^{2}$ and endocrine ${ }^{3}$ defects in older children.

Despite general agreement on the importance of intrapartum hypoxia, the methods for its diagnosis lack specificity and the methods for its assessment are difficult to quantify especially for comparison..$^{4-6}$ A cumulative measure of the metabolic damage due to hypoxia would therefore be helpful.

The metabolic damage due to hypoxia can be measured by the reduction in intracellular ATP.

\footnotetext{
${ }^{*}$ Present address: Department of Paediatrics and Neonatal Medicine, Hammersmith Hospital, Du Cane Road, London W12 OHS.
}

Accepted for publication 18 January 1982
Because serial tissue samples are not available in clinical practice, means of estimating ATP breakdown by non-invasive methods are needed. Since some of the metabolic products of ATP breakdown, hypoxanthine and xanthine, can escape from the cell, concentrations of these oxypurines in extracellular fluids can reflect ATP breakdown. These oxypurines can now be estimated specifically by methods of sufficient sensitivity. ${ }^{7}$ A significant negative correlation between hypoxanthine and xanthine concentrations and relative ATP concentration has been shown in human placenta. ${ }^{8}$ Clinically the raised hypoxanthine and xanthine concentrations in meconium-stained amniotic fluid and in the later stage of labour ${ }^{9}$ with the raised urinary hypoxanthine concentrations in newborn associated with birth complications ${ }^{10}$ suggested that renal excretion of oxypurines by newborn infants could reflect intrapartum hypoxia.

We report increased hypoxanthine and xanthine 
excretion by infants showing neurological damage in a group defined as suffering from intrapartum hypoxia by one or more of the criteria of meconium aspiration, Apgar score of $\leqslant 6$ at $5 \mathrm{~min}$, or a blood $\mathrm{pH}$ of $\leqslant 7.2$ at early postnatal sampling. After an acute period of hypoxia in four newborn infants the prolonged increase in oxypurine excretion suggested that increased excretion can quantify serious metabolic damage at least throughout the period of labour. A possible explanation for the persistence of increased oxypurine excretion 40 or more hours after the return of oxygen supply to normal is suggested.

\section{Materials and methods}

\section{CLINICAL DATA}

Northwick Park is a large general hospital, with a perinatal department, delivering 3400 infants per year. High-risk deliveries are attended by paediatricians who carry out all the neonatal resuscitation. Babies of more than 34 wk gestation, in the absence of sedation by maternal drugs, were defined as asphyxiated if the Apgar score at 5 min was $\leqslant 6$, if arterial or well perfused capillary blood $\mathrm{pH}$ was $\leqslant$ $7 \cdot 2$ after resuscitation or if there was meconium aspiration-that is, meconium seen in the trachea or typical clinical and radiological features of meconium aspiration). During a period of 16 months, 40 infants met these criteria. All significantly asphyxiated infants were admitted to the Special Care Baby Unit and to reduce cerebral oedema, fluids were restricted to $30-40 \mathrm{ml} / \mathrm{kg}$ per day for the first $48 \mathrm{~h}$ and then $60 \mathrm{ml} / \mathrm{kg}$ per day on the third day. Urine was collected from 29 infants, generally in the first $72 \mathrm{~h}$, using adhesive bags. Every 4 to $8 \mathrm{~h}$, the urine sample was removed, labelled with the times of the beginning and end of the collection and frozen at $-20^{\circ} \mathrm{C}$. It was necessary to discard samples from which leaks were noted. Severely affected infants did not pass collectable volumes of urine for variable periods after birth; in these cases collections were started as soon as practicable.

Babies were carefully monitored for apnoea, arterial or transcutaneous $\mathrm{Po}_{2}$, plasma glucose, bilirubin and calcium, blood pressure, renal and cardiac function. Intravenous fluids were given initially to the more seriously ill babies. A daily neurological examination was carried out by one of us (AGLW) using the examination of Dubowitz and Dubowitz ${ }^{11}$ which used visual and auditory responses as well as posture, active and passive tone in the trunk and limbs, tendon reflexes and neonatal responses such as the Moro and grasp. Neck extensor hypertonia, a good sign of insult to the central nervous system, ${ }^{12}$ was specifically looked for in all babies. The degree of irritability and consolability was noted as well as any sedation given. Seizures were described and timed by the nurses or AGLW. Phenobarbitone and paraldehyde were used as anticonvulsants.

The neurological classification of neonates is a vast and complex subject and it was decided to divide up the babies into groups that any experienced paediatrician could recognise.

1 Infants with normal tone, alertness and neonatal responses.

2 Infants with diminished or altered neonatal responses and mild variations in tone, lasting less than $48 \mathrm{~h}$.

3 Infants with diminished or altered neonatal responses and variations in tone, lasting more than $48 \mathrm{~h}$.

4 Pathological irritability requiring sedation.

5 Neck extensor hypertonia as well as altered responses and tone lasting under $48 \mathrm{~h}$.

6 Neck extensor hypertonia and altered responses and tone lasting more than $48 \mathrm{~h}$.

7 Infants having convulsions.

\section{BIOCHEMICAL DATA}

Since there were large variations in the results from short periods of collection "pooled" results from periods of about $10 \mathrm{~h}$ have been used. Although 24 or even $48 \mathrm{~h}$ periods would minimise the effects of errors in collections, such long periods would obscure abnormal trends. Urine was stored at $4^{\circ} \mathrm{C}$ or $-20^{\circ} \mathrm{C}$ until analysis.

Some preliminary purification of urine was necessary to remove ultraviolet absorbing compounds which could otherwise interfere with identification and measurement of purines and pyrimidines by high pressure liquid chromatography (HPLC). Removal of the majority of ultraviolet absorbing impurities was achieved by the cation exchange resin, Zerolit 225 (BDH). This was suspended in 1 $\mathrm{mol} / \mathrm{l} \mathrm{HCl}$, and then washed exhaustively with distilled water until the $\mathrm{pH}$ of the washings was 4-5. Of this resin, $0.5 \mathrm{ml}$ was introduced into a Pasteur pipette plugged with glass wool. Urine $(0.5 \mathrm{ml})$ was added and the column then eluted with $6 \mathrm{ml}$ distilled water, followed by $5 \mathrm{ml} 1 \mathrm{~mol} / \mathrm{l} \mathrm{HCl}$. The flow rate through the column was $1-2 \mathrm{ml} / \mathrm{min}$. Only the acid fraction was collected, which was adjusted to $\mathrm{pH}$ 4-5 with solid potassium dihydrogen phosphate and $10 \mathrm{~mol} / \mathrm{l}$ sodium hydroxide and filtered through a $0.5 \mu \mathrm{m}$ Millipore filter prior to HPLC. This procedure removed the majority of ultraviolet absorbing impurities and thymine, inosine, uridine and uric acid, which were all eluted with water.

However, xanthine, hypoxanthine, guanine, 7-methylguanine, cytidine, guanosine and cytosine 
were eluted, with good recoveries, by the acid. Since the main objective was to determine the effects of hypoxia on purine excretion the loss of some compounds other than hypoxanthine and xanthine in the water wash was acceptable. The efficiency of our procedure was constantly monitored by the extraction of standard solutions of xanthine and hypoxanthine; mean ( \pm SEM) recoveries with one representative batch of Zerolit 225 were $75 \pm 2.2 \%$ for hypoxanthine and $87 \pm 4.1 \%$ for xanthine $(n=4)$.

The purified extracts were then analysed by HPLC using absorption at 254 and $280 \mathrm{~nm}$ for detection. Specificity was achieved by this dual wavelength method and the high plate count of the columns used combined with checks by enzymic removal of peaks. The HPLC part of the method has been described and evaluated in some detail.

Two normal series of infants have been studied using these methods with similar results; one set of such results has been statistically evaluated. ${ }^{13}$ Excretion was calculated per kg body weight per hour and recorded for the relevant age in hours.

The clinical and biochemical data were independently classified into at least three categories-for example, mild, moderate and marked abnormalities then the two sets of data jointly reviewed. In some cases it was possible to achieve approximate ranking of patients within some clinical categories ${ }^{4}$ to compare with the quantitative excretion data.

\section{Results}

\section{NEUROLOGICAL ABNORMALITY AND}

OXYPURINE EXCRETION

In "asphyxiated" infants there was agreement between the degree of neurological abnormality and the magnitude of the oxypurine excretion. The results for different types of neurological abnormality are shown in Fig. 1-6 in which neurological abnormalities persisting for shorter or longer than $48 \mathrm{~h}$ are distinguished. The patterns of results and their heterogeneous nature make the extensive presentation advisable before simplifying assumptions are used to condense some of the data into Tables 1 and 2. More clinical details are included for those infants from whom extensive urine data was obtainable (Table 1).

For those infants who fulfilled the initial criteria of intrapartum hypoxia but were normal neurologically, group 1, the oxypurine excretion (Fig. 1) was normal. Although the initial fall in patient 2 is probably an abnormal trend-none of these four infants showed any persistent abnormality. The mean (SEM) excretion was for hypoxanthine 19.1 (7.5) and for xanthine $18.2(6.1) \mathrm{nmol} / \mathrm{h}$ per $\mathrm{kg}$ which were similar to those for normal infants. ${ }^{13}$
The oxypurine excretion of seven infants with mild, altered or incomplete neurological responses for a period of less than $48 \mathrm{~h}$, group 2, is shown in Fig. 2. The results for four similar infants in whom the neurological abnormalities persisted for longer than 48 h, group 3, are shown in Fig. 3. In Fig. 2 the hypoxanthine excretion, often exceeding the 98th centile, was greater than that of xanthine which was largely "normal" although clustered at higher levels than excretion by "normal" infants (Fig. 1). Overall excretion of both oxypurines showed a fall over 20-70 h of age. Patient 6 was neurologically intermediate between groups 2 and 3 that is between the others in Fig. 2 and those in Fig. 3. Since both hypoxanthine and xanthine excretion at about $50 \mathrm{~h}$ of age was abnormally raised his oxypurine excretion was also intermediate between the other values in Fig. 2 and those in Fig. 3. All four infants neurologically abnormal for longer than $48 \mathrm{~h}$ had "abnormally" high excretion of both xanthine and hypoxanthine. In Fig. 3 only one, 12, provided acceptable samples in the first $20 \mathrm{~h}$ of life. In addition the age at which there was a tendency for excretion to fall is possibly greater in Fig. 3 than in Fig. 2.

Two patients 23 and 24 were classified neurologically as cerebral irritability requiring sedation, group 4. Both showed abnormal excretion of hypoxanthine and xanthine. Unfortunately the more severely neurologically affected was only studied between $30-60 \mathrm{~h}$ of age but in this time it was clear that his excretion rate was about $20 \mathrm{nmol} / \mathrm{h}$ per $\mathrm{kg}$ higher than in infant 24 at the same age. It was thus possible to "rank" these two infants by both sets of criteria.

Oxypurine excretion by six infants with neck extensor hypertonia, groups 5 and 6 , is shown in Figs. 4 and 5. Those with this finding for less than 48 $h$ are shown in Fig. 4; two of the three showing at least one abnormally high value. In contrast, the sustained high excretion of those showing $\geqslant 48 \mathrm{~h}$ of neck extensor hypertonia is shown in Fig. 5. The one available value in patient 21 since it is high at the age of about $70 \mathrm{~h}$ suggests that his excretion might have been similar to that of the other two seriously affected infants. In group 7 , three patients with convulsions (for $<24 \mathrm{~h}$ ) were studied. Infant 26 showed an excretion pattern similar to those in Fig. 5. Infant 25 had only two values which were high, 80 and 82 $\mathrm{nmol} / \mathrm{h}$ per $\mathrm{kg}$. These were similar to the high values for patient 26,100 and $65 \mathrm{nmol} / \mathrm{h}$ per $\mathrm{kg}$; both 25 and 26 showed these abnormalities at around $20 \mathrm{~h}$ of age. The other patient, 27 , showed results entirely within the normal range and no consistent trend. This child was not noted to be abnormal neurologically until skilled examination at about $24 \mathrm{~h}$ of age but thereafter was found to have persistent neck 


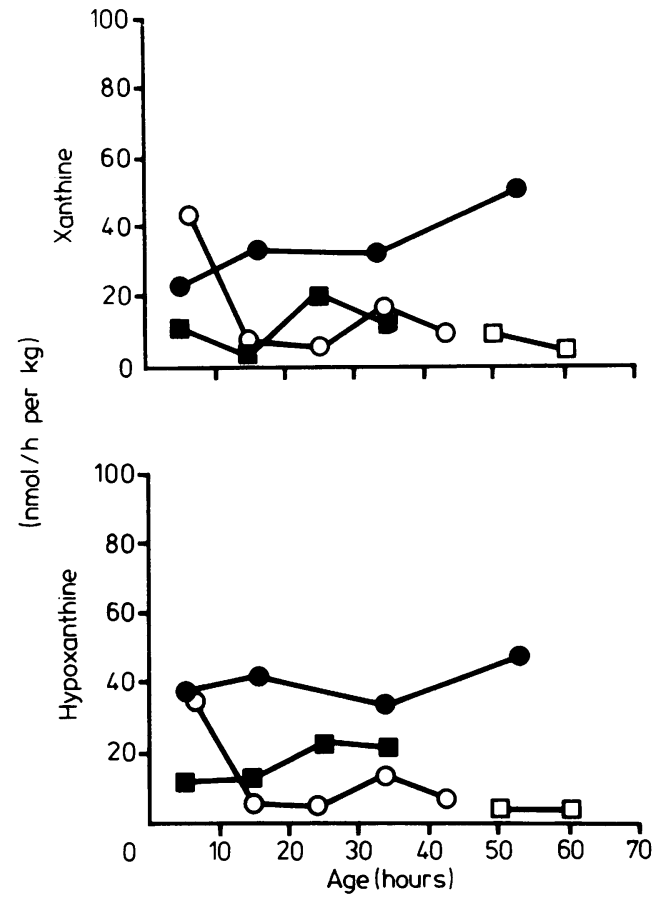

Fig. 1

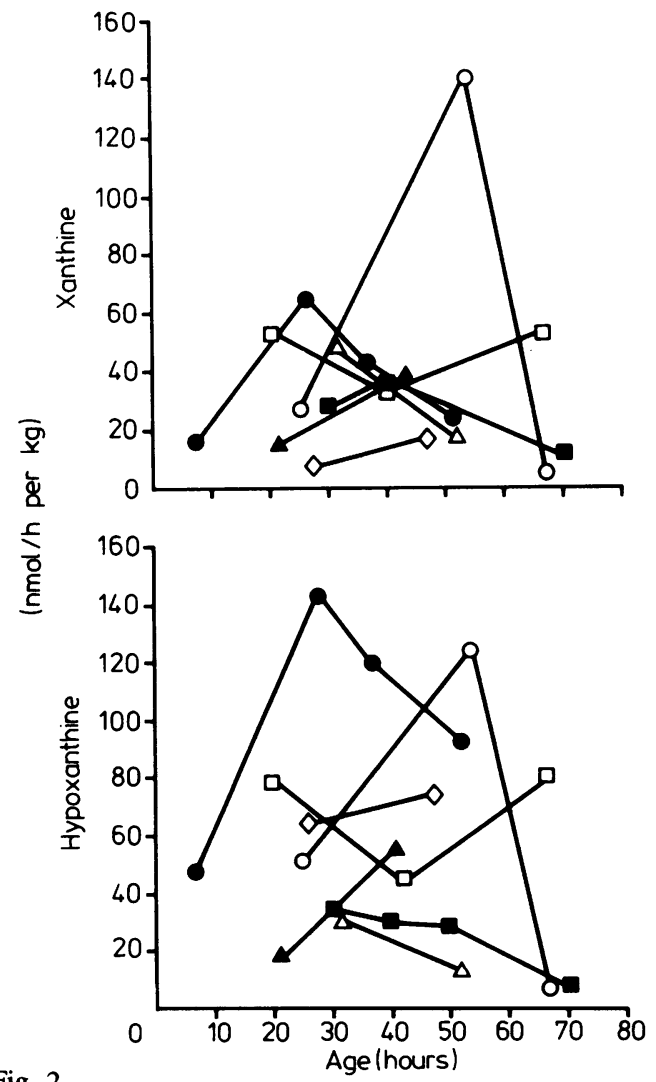

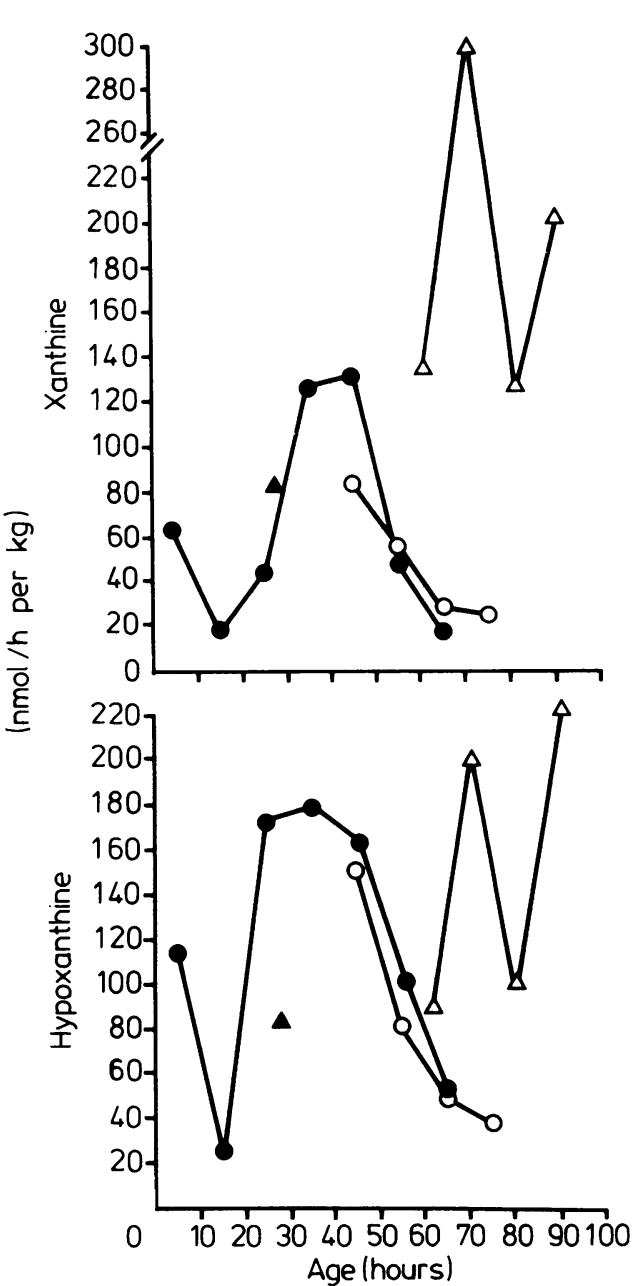

Fig. 3

Fig. 1 Hypoxanthine (lower) and xanthine (upper) excretion by infants 1 , 2 O, 1 and $4 \square$ with no neurological abnormalities, group 1

Fig. 2 Hypoxanthine (lower) and xanthine (upper) excretion by infants $50,6 \bigcirc, 7 \square, 8 \square, 9 \Delta, 10 \triangle$, and 11 $\diamond$ with diminished or altered neonatal responses and variations in tone lasting less than $48 \mathrm{~h}$, group 2

Fig. 3 Hypoxanthine (lower) and xanthine (upper) excretion by infants $12 \bigcirc, 13 \bigcirc, 14 \triangle$ and $15 \Delta$ with diminished or altered neonatal responses lasting more than $48 \mathrm{~h}$, group 3

Fig. 2 


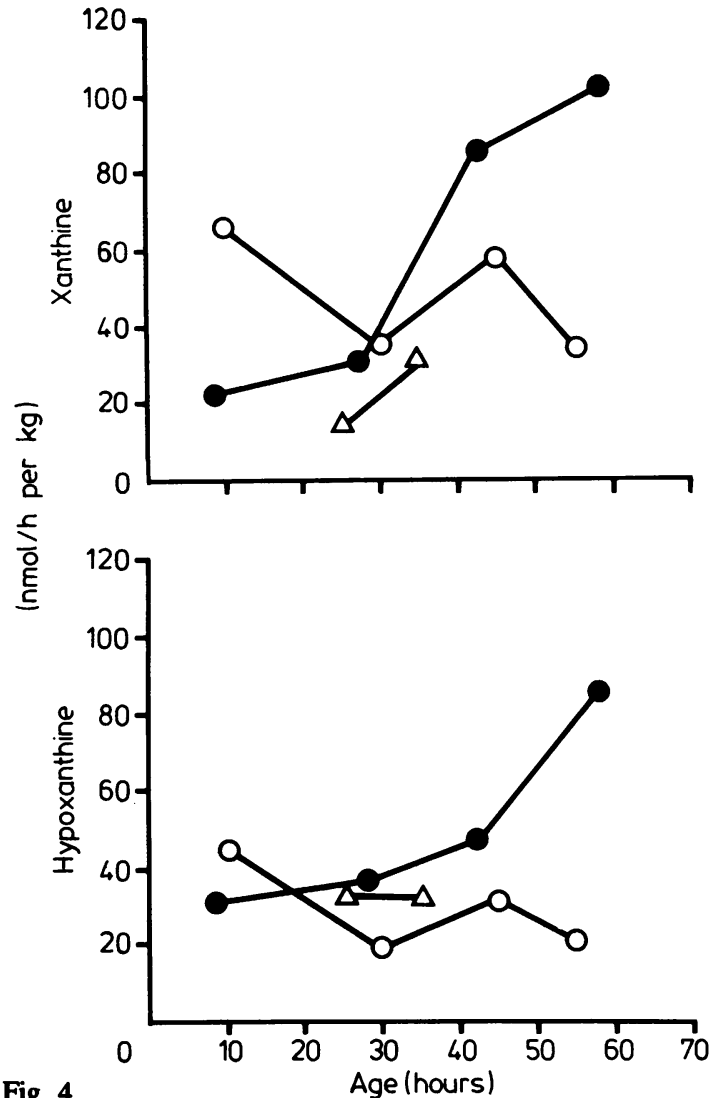

Fig. 4
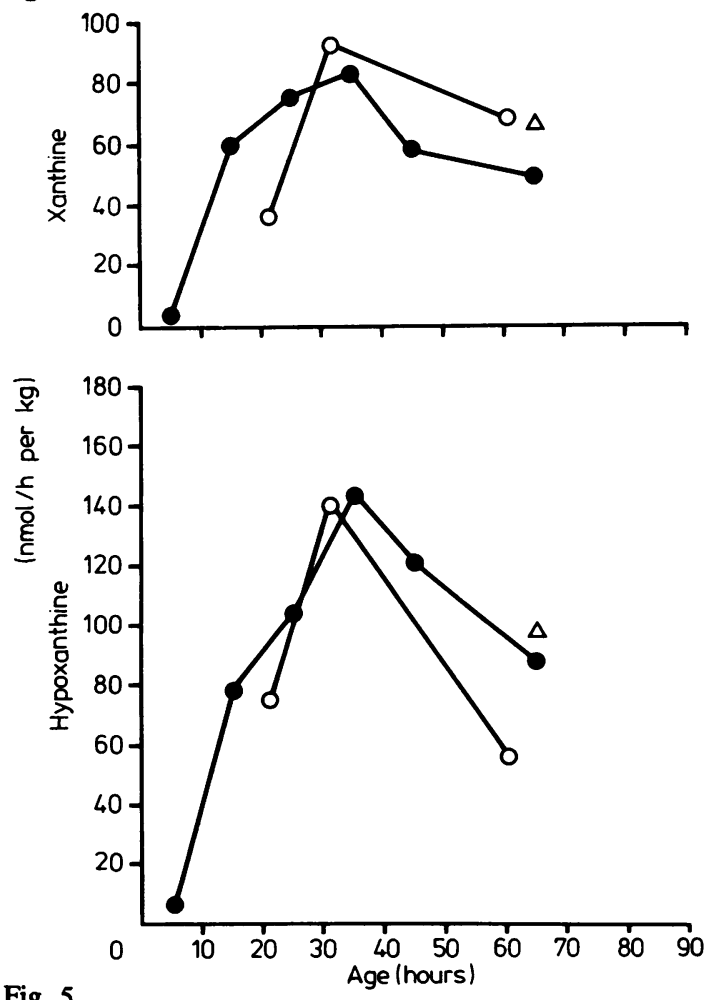

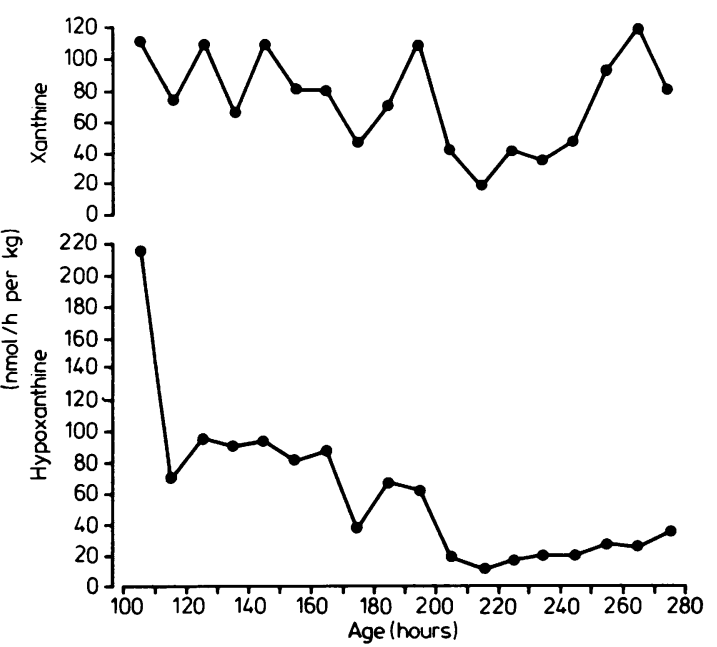

Fig. 6

Fig. 4 Hypoxanthine (lower) and xanthine (upper) excretion by infants $16 \bullet, 17 \bigcirc$ and $18 \triangle$ with neck extensor hypertonia lasting $<48 \mathrm{~h}$, group 5

Fig. 5 Hypoxanthine (lower) and xanthine (upper) excretion in infants 190,200 and $21 \triangle$ with neck extensor hypertonia, altered responses and tone lasting more than 48 h, group 6

Fig. 6 Hypoxanthine (lower) and xanthine (upper) excretion by an infant 220 with marked hypoxic damage, group 7

extensor hypertonia.

Infant 22 in Fig. 6 had the most severe neurological damage of any of our patients including fits for $24 \mathrm{~h}$. The results in Fig. 6 show the most marked delay in starting the study and the most persistently abnormal and highest maximum excretion found.

One patient, 28, had severe neurological abnormalities and hypothyroidism. His hypoxanthine excretions for the periods in hours indicated in brackets from the age of one hour were 42 (31), 45 (11), 8 (21) and 11 (9). His xanthine excretion for the same periods were $43,50,12$ and $19(\mathrm{nmol} / \mathrm{h}$ per $\mathrm{kg}$ ). There was therefore a reduction in excretion with age which is probably pathological but absolute excretion was at the upper limits of the normal range for euthyroid infants.

The changing patterns of excretion rates in infants after intrapartum hypoxia (Figs.1-6) suggested that it would be justifiable to examine the "total" increase in hypoxanthne excretion where enough data were available. In order to avoid normal excretion rates loading the figures, 50 was subtracted

Fig. 5 
Table 1 Summaries of obstetric, paediatric and biochemical assessments of infants with severe intrapartum hypoxia

\begin{tabular}{|c|c|c|c|c|c|c|c|}
\hline Infant & $\begin{array}{l}\text { Gest age } \\
(w k)\end{array}$ & $\begin{array}{l}\text { Birth wt } \\
(g)\end{array}$ & Obstetric complications & $\begin{array}{l}\text { Apgar score } \\
1 \mathrm{~min}, 5 \mathrm{~min}\end{array}$ & $\begin{array}{l}\text { Initial } \\
p H\end{array}$ & $\begin{array}{l}\text { Neurological } \\
\text { abnormality }\end{array}$ & $\begin{array}{l}\text { Total increase } \\
\text { in hypoxanthine } \\
\text { excretion } \\
(\text { nmol } / \mathrm{kg})^{*}\end{array}$ \\
\hline 5 & 36 & 1930 & $\begin{array}{l}\text { Pre-eclampsia, antepartum } \\
\text { haemorrhage, intrauterine } \\
\text { growth retardation }\end{array}$ & 2,5 & $7 \cdot 22$ & $\begin{array}{l}\text { Hypotonic for } \\
\text { under } 48 \mathrm{~h}\end{array}$ & 253 \\
\hline 6 & 40 & 4040 & $\begin{array}{l}60 \text { min of unsuccessful } \\
\text { forceps and ventouse } \\
\text { delivery }\end{array}$ & 1,5 & $7 \cdot 25$ & $\begin{array}{l}\text { Irritable, sedation } \\
\text { for under } 48 \mathrm{~h}\end{array}$ & 74 \\
\hline 12 & 35 & 2620 & $\begin{array}{l}\text { Pre-eclampsia, breech, } \\
\text { 2nd twin }\end{array}$ & 4,6 & $7 \cdot 17$ & $\begin{array}{l}\text { Respiratory distress, } \\
\text { ventilated, pneumothorax, } \\
\text { hypotonic for } 6 \text { days }\end{array}$ & 473 \\
\hline 24 & 39 & 3400 & $\begin{array}{l}\text { Pre-eclampsia, type } 2 \text { dips } \\
\text { of fetal heart } 21 / 2 \text { hours } \\
\text { before delivery }\end{array}$ & 4,6 & $7 \cdot 14$ & $\begin{array}{l}\text { Pathologically } \\
\text { irritable for } 3 \text { days }\end{array}$ & 93 \\
\hline 19 & 35 & 2380 & $\begin{array}{l}\text { Fetal tachycardia, reduced } \\
\text { beat to beat variation and } \\
\text { long bradycardia }\end{array}$ & 1,3 & $7 \cdot 13$ & $\begin{array}{l}\text { Neck extensor, } \\
\text { hypertonia } 3 \text { days, } \\
\text { irritable } 4 \text { days }\end{array}$ & 331 \\
\hline 26 & 41 & 3610 & $\begin{array}{l}\text { Pre-eclampsia, loss of beat } \\
\text { to beat variation, fetal } \\
\text { tachycardia } 7 \text { hours before } \\
\text { delivery }\end{array}$ & 3,5 & $7 \cdot 17$ & $\begin{array}{l}\text { Convulsions day } 1 \text {, } \\
\text { Neck extensor } \\
\text { hypertonia for } 3 \text { days }\end{array}$ & 153 \\
\hline 22 & 39 & 2290 & $\begin{array}{l}\text { Pre-eclampsia. 1st twin. } \\
\text { Fetal bradycardia then } \\
\text { baseline tachycardia for } \\
3 \text { hours }\end{array}$ & 2,4 & $7 \cdot 13$ & $\begin{array}{l}\text { Convulsions for } 24 \mathrm{~h} \text {. } \\
\text { Neck extensor hypertonia } \\
\text { for } 7 \text { days. Acute } \\
\text { tubular necrosis. }\end{array}$ & 418 \\
\hline
\end{tabular}

*All positive values $>50$. All urine collections were started within four hours of birth except for 22 who started at the age of $100 \mathrm{~h}$.

Table 2 Association between neurological state and increased hypoxanthine excretion after intrapartum hypoxia

\begin{tabular}{|c|c|c|c|c|c|c|}
\hline \multirow{2}{*}{$\begin{array}{l}\text { Neurological } \\
\text { category }\end{array}$} & \multirow[t]{2}{*}{ No of infants } & \multicolumn{2}{|c|}{ Initial pH after resuscitation } & \multicolumn{3}{|c|}{ Increase in hypoxanthine excretion * $(\mathrm{nmol} / \mathrm{kg}$ ) } \\
\hline & & Mean & Range & Mean & Range & $\underline{\underline{c}}$ \\
\hline $\begin{array}{l}1 \\
2(<48 h) \\
3(>48 h) \\
4 \\
5(<48 h) \\
6(>48 h) \\
7\end{array}$ & $\begin{array}{l}4 \\
7 \\
4 \\
2 \\
3 \\
3 \\
3\end{array}$ & $\begin{array}{l}7 \cdot 21 \\
7 \cdot 21 \\
7 \cdot 20 \\
7 \cdot 22 \\
7 \cdot 21 \\
7 \cdot 13 \\
7 \cdot 20\end{array}$ & $\begin{array}{l}7 \cdot 13-7 \cdot 34 \\
7 \cdot 02-7 \cdot 29 \\
7 \cdot 13-7 \cdot 29 \\
7 \cdot 14-7 \cdot 30 \\
7 \cdot 04-7 \cdot 37 \\
7 \cdot 10-7 \cdot 16 \\
7 \cdot 17-7 \cdot 25\end{array}$ & $\begin{array}{c}0 \\
16 \cdot 9 \\
70 \cdot 6 \\
29 \cdot 2 \\
3 \\
44 \cdot 4 \\
31 \cdot 2\end{array}$ & $\begin{array}{c}0 \\
0-51 \\
34-106 \\
23-35 \\
0-9 \\
37-49 \\
21-42\end{array}$ & \\
\hline
\end{tabular}

*All positive values $>50$.

from each 10 hour rate and then all positive data summed. The value of 50 was chosen since the 98 th centile had been estimated to lie between 50 and 60 $\mathrm{nmol} / \mathrm{h}$ per $\mathrm{kg}$ for hypoxanthine and not to vary with age. ${ }^{13}$ This total increase in hypoxanthine excretion or "incremental area under the curve" in Figs. 1-6 should allow comparisons to be made between different clinical groups. More complete clinical details for patients for whom such data were available are shown in Table 1 . The overall correlation as in Figs. 1-6 was clear starting from 0 values for infants with no neurological abnormalities (not shown in Table 1) to the highest cumulative excretion for infant 22 (Fig. 6), excluding from the comparison infant 12 who required ventilation and therefore was also hypoxic after delivery.

One objective assessment of the infants after intrapartum hypoxia was from their initial capillary blood $\mathrm{pH}$. This showed little or no correlation with neurological abnormality or with oxypurine excretion (Table 2). The explanation for these findings is suggested by the results in Fig. 7 on an infant with the respiratory distress syndrome who after a normal delivery and good early progress showed a progressive drop in blood $\mathrm{pH}$ to very low levels after which he was mechanically ventilated. The prolonged and marked rise in oxypurine excretion persisted for about $60 \mathrm{~h}$ after the blood $\mathrm{pH}$ had returned to normal. The infant "collapsed" at the point indicated by the arrow although the nature of this collapse could not be defined. Oxypurine excretion and urine volume fell sharply in the succeeding seven hour collection. Figure 8 shows another infant with respiratory distress in whom oxypurine excretion rose markedly about 10 hours after blood $\mathrm{pH}$ had returned to normal. Abnormal excretion persisted for about 50 hours.

In addition to the mechanically ventilated infants, 


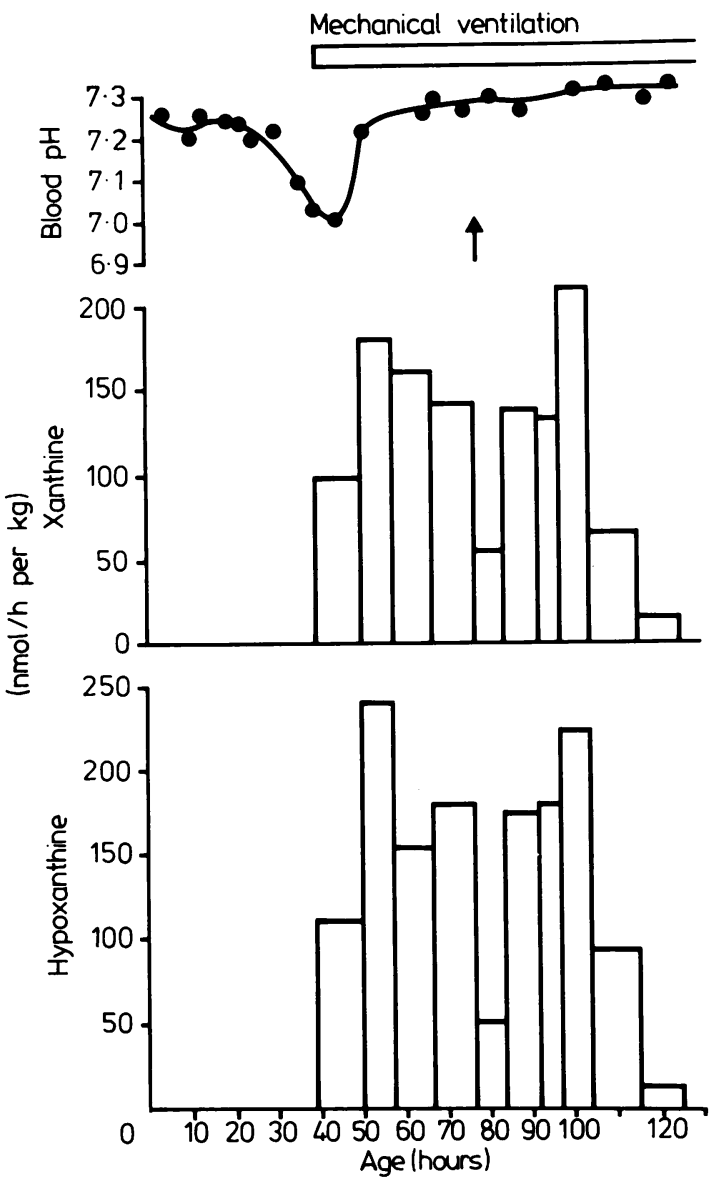

Fig. 7 Hypoxanthine (lower) and xanthine (upper) excretion and blood pH (upper) during mechanical ventilation for the respiratory distress syndrome. The arrow indicates 'collapse'

two infants were studied after apnoeic attacks, another metabolic insult which could be timed. The prolonged and increased oxypurine excretion after two apnoeic attacks is shown in Fig. 9. Another infant was studied after one attack; there was a rise of both hypoxanthine and xanthine excretion to 71 and $75 \mathrm{nmol} / \mathrm{h}$ per $\mathrm{kg}$ in the 15 hours after the attack. The subsequent 13-hour collection showed a normal excretion of $\mathbf{3 3}$ for hypoxanthine and $\mathbf{3 0}$ for xanthine $(\mathrm{nmol} / \mathrm{h}$ per $\mathrm{kg})$. In this subject in whom urine flow was preserved the initial concentrations after the attack were 722 and $274 \mu \mathrm{mol} / \mathrm{l}$ for hypoxanthine and xanthine respectively. Both of these are markedly raised from the normal values of about 50 .

One defect of the objective presentation of heterogeneous clinical and biochemical data, even
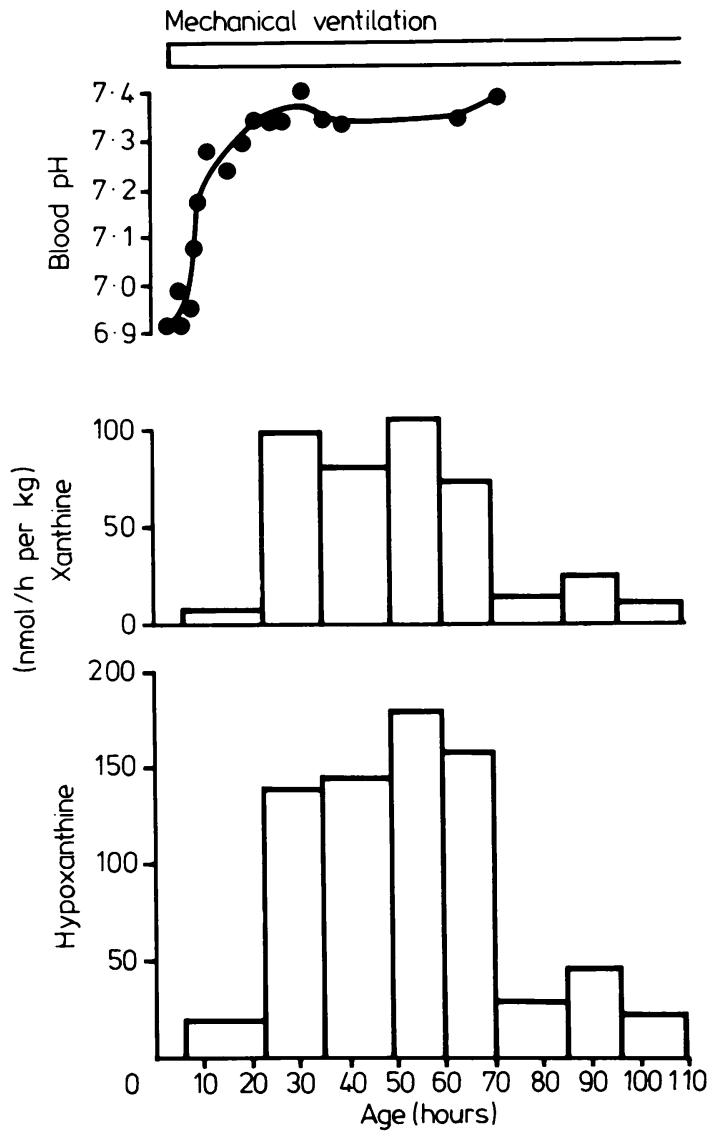

Fig. 8 Hypoxanthine (lower) and xanthine (upper) excretion and blood pH (upper) during mechanical ventilation for the respiratory distress syndrome.

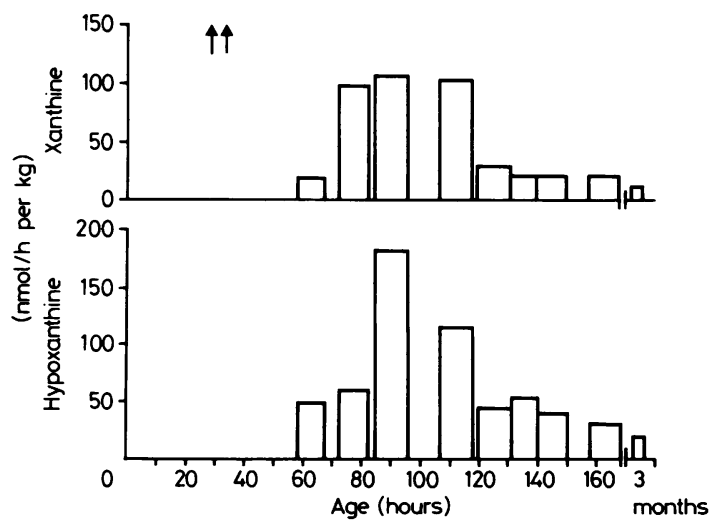

Fig. 9 Hypoxanthine (lower) and xanthine (upper) excretion by an infant after two attacks of apnoea indicated by the arrows. 
as graphs like Figs. 1-6, is the difficulties in allowing the overall pattern between neurological groups to be readily seen. This pattern is visible in Table 2 in which mean increased hypoxanthine excretion is higher in the infants with neurologically defined abnormalities which were present for $>48 \mathrm{~h}$ compared to those in whom such abnormalities lasted < $48 \mathrm{~h}$. The hypoxanthine excretion is treated similarly to the results for Table 1 .

\section{Discussion}

The effect of an acute reduction in ATP concentrations in cells is to increase the outflow of AMP metabolites maintaining the ATP concentrations relative to AMP. ${ }^{14}$ In other words, the energy charge,

$$
\frac{\{\text { ATP }\}+1 / 2\{\text { ADP }\}}{\{\text { ATP }\}+\{\text { ADP }\}+\{\text { AMP }\}}
$$

falls more slowly than the total adenine nucleotide concentration. ${ }^{8}$ In this way an acute reduction of ATP in man produces an increased excretion of hypoxanthine..$^{15}$ Some of our asphyxiated patients showed a high initial excretion (Fig. 1, infant 2; Fig. 3, infant 12). This is the predictable consequence of a marked reduction in cellular ATP concentrations. ${ }^{14}$

The little available previous work is consistent with our findings in normal and in pathological conditions. Urinary excretion of urate, the metabolite of hypoxanthine, was previously found to be raised in idiopathic respiratory distress and this was due to an increase in production. ${ }^{16}$ These findings were extended to show that urate and xanthine excretion were higher in respiratory distress. ${ }^{17}$ Our findings of both raised hypoxanthine and xanthine excretion are probably due to the use of a more sensitive method, HPLC with sensitive ultraviolet absorbance detection. Another difference is that we have mainly studied intrapartum hypoxia. In this way we have avoided the increased oxypurine excretion which occurs after exercise..$^{15}$ Respiratory efforts in our two mechanically ventilated infants were minimal.

In our data after intrapartum or postpartum hypoxia the recurring pattern of rising excretion may be simply explained by early renal "failure" associated with a reduction in urine flow since renal failure after intrapartum hypoxia is obvious on the first day of life. ${ }^{19}$ Varying degrees of renal damage follow intrapartum hypoxia ${ }^{20}$ and were seen in our patients generally as initial oliguria or even anuria for up to $72 \mathrm{~h}$. In contrast more than $90 \%$ of normal infants pass urine on the first day of life..$^{21}$

The persistence of raised excretion for $\mathbf{4 0}$ or more hours after hypoxia was unexpected. In our studies
(Figs. 7 and 8) oxygen supply and the extent of anaerobic glycolysis as reflected by the blood $\mathrm{pH}$ were returned to physiological levels rapidly. A similar rapid return of blood $\mathrm{pH}$ to normal is seen after delivery. ${ }^{22}$ The immediate adjustments to maintain relative ATP concentration ${ }^{14}$ probably last no longer than about $5 \mathrm{~h} .{ }^{23}$ It is therefore necessary to search for some other mechanism to explain the raised excretion over 40 or more hours.

There is some experimental evidence which could explain our findings. In the mouse renal ischaemia lasting less than one hour has, after reperfusion, been followed by a rapid return of energy charge to control levels but there was a slower return of total adenine nucleotide concentrations to about $60-70 \%$ of control values. Total adenine nucleotide concentrations then returned even more slowly to control values over the next $24 \mathrm{~h}$. If ischaemia lasted more than one hour then, if there was any recovery all the above events were slower. ${ }^{24}$ These changes may also take place in the human kidney and may be associated with increased oxypurine excretion. Human kidneys after prolonged ischaemia subsequently show an increased outflow of ATP metabolites. The extent of this outflow is related to the viability of these kidneys when grafted. ${ }^{25}$

The inefficiency of mechanisms maintaining AT after severe "asphyxia" when substrate supply i completely restored may be due to a series of persis tent mitochondrial defects-for example, in succinate oxidase activity, which are correlated with the adenine nucleotide content of such mitochondria. ${ }^{26}$ These mechanisms may be important in the perinatal period in view of the developmental changes in mitochondria at this time. ${ }^{27}$

There are two patients in whom initial independent classification by neurological damage and by oxypurine excretion did not produce concordant results. One was explained by hypothyroidism. Since ATP turnover is reduced in hypothyroidism ${ }^{28}$ and since increased oxypurine excretion is found in exercise ${ }^{1518}$ linked with ATP "turnover", ${ }^{29}$ the normal range of oxypurine excretion in hypothyroidism should be lower than from euthyroid subjects. Unfortunately urine collections were not long enough to ensure that our patient had returned to his own "control" values. It is probable that this infant's oxypurine excretion was relatively high. It is also possible that the hypothyroidism has contributed, directly or even indirectly, by altering susceptibility to hypoxic damage. Hyperthyroidism has been suggested to predispose to areas of tissue hypoxia. $^{30}$

There was one unexplained anomaly in our results, patient 27 with the persistent neurological sign of neck extensor hypertonia noted $24 \mathrm{~h}$ after 
delivery. It is possible that the episode of severe hypoxia occurred well before the onset of labour. Alternatively, an intrapartum episode may have spared the kidneys and the heart ${ }^{31}$ and possibly other systems despite damage to the CNS. Since there is no unequivocal proof of any cause for the neurological damage in infant 27 , this discrepancy is unexplained.

The prolonged increase in oxypurine excretion after postpartum hypoxia shows that urinary oxypurine excretion should reflect severe intrapartum hypoxia occurring at any time in labour since this is unlikely to last for more than $40 \mathrm{~h}$. The above data show that a timed collection of a minimum of $10 \mathrm{~h}$ preferably $20-50 \mathrm{~h}$ duration should distinguish "asphyxiated" infants and quantify the degree of metabolic damage. Existing data suggests this timed urine collection should be started about $24 \mathrm{~h}$ after birth or thereafter if urine flow is not yet established. Our results suggest that the assessment of metabolic damage by oxypurine excretion is sensitive and has a large range. However, despite the clinical difficulties, more systematic sampling is needed to determine optimum sampling and data treatment. The somewhat arbitrary procedures in Tables 1 and 2 are probably not optimal. Considerable simplification would appear to be practicable once initial research has provided a sound basis for such decisions. Since little comparable data are available further work is needed to explore the possible applications of our findings.

We are grateful to Sister C Lawrence and SB Coade for their help in the ward and the laboratory.

\section{References}

' Illingworth RS. Why blame the obstetrician? a review. Br Med J 1979;i:797-801.

${ }^{2}$ D'Souza SW, McCartney E, Nolan M, Taylor IG. Hearing, speech and language in survivors of severe perinatal asphyxia. Arch Dis Child 1981;56:245-52.

${ }^{3}$ Steendijk R. Diagnostic and aetiologic features of idiopathic and symptomatic growth hormone deficiency in the Netherlands. Helv Paed Acta 1980;35:129-39.

${ }^{4}$ Brown JK. Infants damaged during birth. In: Hull D, ed. Recent advances in paediatrics. Edinburgh: Churchill-Livingstone, 1976:35-86.

${ }^{5}$ Hill LM. Diagnosis and management of fetal distress. Mayo Clin Proc 1979;54:784-93.

- O'Connor MC, Harkness RA, Simmonds RJ, Hytten FE. The measurement of hypoxanthine, xanthine, inosine and uridine in umbilical cord blood and fetal scalp blood samples as a measure of fetal hypoxia. $\mathrm{Br} J$ Obstet Gynaecol 1981;88:381-90.

' Simmonds RJ, Harkness RA. High performance liquid chromatographic methods for base and nucleoside ana'ysis in extracellular fluids and in cells. $J$ Chromatogr 1981;226:36981
${ }^{8}$ Simmonds RJ, Coade SB, Harkness RA, Drury L, Hytten FE. Nucleotide, nucleoside and purine base concentrations in human placentae. Placenta 1982;3:29-38

9 O'Connor MC, Harkness RA, Simmonds RJ, Hytten FE. Raised hypoxanthine, xanthine and uridine concentrations in meconium stained amniotic fluid and during labour. $\mathrm{Br} \mathrm{J} \mathrm{Obs-}$ tet Gynaecol 1981;88:375-80.

${ }^{10}$ Manzke H, Dorner K, Grunitz J. Urinary hypoxanthine, xanthine and uric acid excretion in newborn infants with perinatal complications. Acta Paed Scand 1977;66:713-7.

"Dubowitz L, Dubowitz V. Neurological assessment of the preterm and full term newborn. Clinics in development medicine 79. London: Spastics International Medical Publications, 1981.

${ }^{12}$ Amiel-Tyson C, Korobkin R, Esquevaucouloux M. Neck extensor hypertonia: a clinical sign of insult to the central nervous system of the newborn. Early Hum Dev 1977;1/2:181-90.

${ }^{13}$ Harkness RA, Simmonds RJ, Edwards AC, Valman HB, Dore $C J$. Hypoxanthine and xanthine excretion by normal newborn infants. Submitted for publication.

14 Atkinson DE. Cellular energy metabolism and its regulation. London: Academic Press, 1977.

15 Sutton JR, Toews CJ, Ward GR, Fox IH. Purine metabolism during strenuous muscular exercise in man. Metabolism 1980;29:254-60.

${ }^{16}$ Raivio KO. Neonatal hyperuricaemia. J Pediatr 1976;88:625-30.

17 Jensen MH, Brinklov MM, Lillqvist K. Urinary loss of oxypurines in hypoxic premature neonates. Biol Neonate 1980;38:40-8.

${ }^{18}$ Nasrallah S, Al-Khalidi U. Nature of purines excreted during muscular exercise. J Appl Physiol 1964;19:246-8.

${ }^{19}$ Dauber IM, Krauss AN, Symchych PS, Auld PAM. Renal failure following perinatal anoxia. J Pediatr 1976;88:851-5.

${ }^{20}$ Daniel SS, James LS. Abnormal renal function in the newborn infant. J Pediatr 1976;88:856-8.

${ }^{21}$ Moore ES, Galvez MB. Delayed micturition in the newborn period. J Pediatr 1972;80:867-73.

${ }^{22}$ Miller FC, Sacks DA, Yeh S-Y, et al. Significance of meconium during labour. Am J Obstet Gynecol 1975;122:573-80.

${ }^{23}$ Engelman K, Watts RWE, Klinenberg JR, Sjoerdsma A, Seegmiller JE. Clinical, physiological and biochemical studies of a patient with xanthinuria and phenochromocytoma. Am J Med 1964;37:839-61.

${ }^{24}$ Warnick CT, Lazarus HM. Recovery of nucleotide levels after cell injury. Can J Biochem 1981;59:116-21.

${ }^{25}$ Buhl MR. Oxypurine excretion during kidney preservation: an indicator of ischaemic damage. Scand J Clin Lab Invest 1976;36:169-74.

${ }^{26}$ Nakazawa T, Nunokawa T. Energy transduction and adenine nucleotides in mitochondria from rat liver after hypoxic perfusion. J Biochem 1977;82:1575-83.

${ }^{27}$ Sutton R, Pollak JK. The increasing adenine nucleotide concentration and the maturation of rat liver mitochondria during development. Differentiation 1978;12:15-21.

${ }^{28}$ Edelman IS, Ismail Beigi F. Thyroid thermogenesis and active sodium transport. Recent Prog Horm Res 1974;30:235-57.

${ }^{29}$ Lowenstein JM. Ammonia production in muscle and other tissues: the purine nucleotide cycle. Physiol Rev 1972;52:382414.

${ }^{30}$ Piatnek-Leumissen D, Olson RE. Cardiac failure in the dog as a consequence of exogenous hyperthyroidism. Circulation Res 1967;20:242-52.

${ }^{31}$ Cabal LA, Devaskar U, Siassi B, Hodgman JE, Emmanouilides G. Cardiogenic shock associated with perinatal asphyxia in preterm infants. $J$ Pediatr 1980;96:705-10.

Requests for reprints to: Dr RA Harkness, Division of Perinatal Medicine, Clinical Research Centre, Watford Road, Harrow, HA1 3UJ, Middlesex, England. 